\title{
A comparative study of artificial intelligence and conventional techniques for rainfall-runoff modeling
}

\section{VIJAY KUMAR SINGH, BHASKAR PRATAP SINGH, ASHISH KUMAR AND VIVEKANAND}

See end of the Paper for authors' affiliation

Correspondence to :

VIJAY KUMAR SINGH

Department of Soil and Water Conservation Engineering,

G.B. Pant University of Agriculture and Technology, Pantnagar, U.S. NAGAR (UTTARAKHAND) INDIA Email:vijaysinghswce @ gmail.com
- ABSTRACT : The essential for accurate modeling of the rainfall-runoff process has grown rapidly in the past decades. However, considering the high stochastic property of the process, many models are still being developed in order to define such a complex phenomenon. In this study, two AI-based models which are reliable in capturing the periodicity features of the process are introduced for river rainfall-runoff modeling. In the first model, the ANN model, an ANN is used to five different type training algorithms namely momentum, Quickprop, Delta-Bar-Delta, Conjugate Gradient and Levenberg Marquardt. In the second model, ANFIS model trained used to two different type membership function (MFs) viz., Gaussian and generalized bell and conventional techniques was used multiple linear regression (MLR). The artificial intelligence performed better than the conventional techniques for rainfall-runoff modelling of study area. The ANFIS models performing the best results, ANN models gives the satisfactory results and MLR model having poor result in runoff prediction for Arpa River basin. Also gamma test (GT) was used for identifying the best input combination of input variables.

- KEY WORDS : Artificial neural network, Adaptive neural-fuzzy inference system, Multiple linear regression, Gamma test

- HOW TO CITE THIS PAPER : Singh, Vijay Kumar, Singh, Bhaskar Pratap, Kumar, Ashish and Vivekanand (2017). A comparative study of artificial intelligence and conventional techniques for rainfall-runoff modeling. Internat. J. Agric. Engg., 10(2) : 441-449, DOI: 10.15740/HAS/IJAE/10.2/ 441-449. 